\title{
Maxillary Second Molar with a Rare Palatal Root Canal Morphology: A Case Report
}

\author{
Pooja Sen ${ }^{1}$, Ashwini B Prasad ${ }^{2}$, Prachi Mital ${ }^{3}$, Deepak Raisingani ${ }^{4}$, Deeksha Khurana ${ }^{5}$, Harshit Srivastava ${ }^{6}$
}

\begin{abstract}
Knowledge of the root canal anatomy and its variations is essential for successful completion of the endodontic treatment. Root canal treatment of maxillary second molars with aberrant canal configuration can be challenging. The incidence of two palatal canals in a palatal root is quite rare in maxillary molars. The novel diagnostic aids such as cone-beam computed tomography (CBCT) help in the successful management of such cases. This case report describes the successful diagnosis and treatment of a maxillary second molar with two palatal canals, merging at the apical third of the root.

Keywords: Cone-beam computed tomography, Maxillary second molar, Root canal treatment, Two palatal canals.

Journal of Mahatma Gandhi University of Medical Sciences \& Technology (2020): 10.5005/jp-journals-10057-0118
\end{abstract}

\section{INTRODUCTION}

One of the major reasons of failure in endodontic treatment is the inability to locate and treat the entire root canal system, which is a result of the lack of knowledge regarding internal or external dental anatomy. ${ }^{1}$ Number of roots and canals can differ, and the literature demonstrates a profound number of anatomical variations. Thus, a comprehensive knowledge of root canal morphology and a good anticipation of their possible morphologic variations are necessary, which will help a dentist to reduce endodontic failure.

While it is not uncommon for maxillary second molars to have three roots with three canals, additional palatal canals are more commonly found in maxillary first molars. ${ }^{2}$ Few clinical case reports exhibit the presence of extrapalatal canals and/or roots in maxillary second molars. ${ }^{3}$ However, studies on maxillary second molars show a low incidence of having two palatal root canals.

Pécora et al. ${ }^{1}$ investigated the anatomy of 370 maxillary molars and the result showed the incidence of having three canals was $75 \%$ for maxillary first, 58\% for second, and $68 \%$ for third molars. Four canals were found in $25 \%$ of maxillary first molars, $42 \%$ of second molars, and $32 \%$ of third molars. Stone and Stroner ${ }^{4}$ reported a single palatal root containing two separate orifices, canals, and foramina; also, they found one single palatal root with one orifice, a bifurcated canal, and two foramina. In 2012, Shojaeian et al. ${ }^{4}$ reported a case of maxillary second molars that had two palatal canals along with furcal enamel pearl.

The present case report describes the endodontic management of a maxillary second molar with two separate palatal canals, merging at the apical third and diagnosed with the help of $C B C T$ scans.

\section{Case Description}

A 35-year-old male patient reported to the Department of Conservative Dentistry and Endodontics with the chief complaint of pain in the upper left back tooth region since 3-4 days. Patient's medical history was noncontributory. The buccal and lingual mucosa was normal. There was no intra or extraoral swelling/sinus present. Oral examination revealed mesioproximal decay in relation to left maxillary second molar (\#27) and previously endodontically
${ }^{1-6}$ Department of Conservative Dentistry and Endodontics, Mahatma Gandhi Dental College and Hospital, Mahatma Gandhi University of Medical Sciences and Technology, Jaipur, Rajasthan, India

Corresponding Author: Pooja Sen, Department of Conservative Dentistry and Endodontics, Mahatma Gandhi Dental College and Hospital, Mahatma Gandhi University of Medical Sciences and Technology, Jaipur, Rajasthan, India, Phone: +91 8384954707, e-mail: sen.pooja41@yahoo.com

How to cite this article: Sen P, Prasad AB, Mital P, et al. Maxillary Second Molar with a Rare Palatal Root Canal Morphology: A Case Report. J Mahatma Gandhi Univ Med Sci Tech 2020;5(1):23-25.

Source of support: Nil

Conflict of interest: None

treated left maxillary first molar (\#26) without coronal prosthesis. The periodontal health was normal. Radiographic examination revealed radiolucency approaching to the pulp with widening of the periodontal ligament space in relation to \#27 (Fig. 1). Also, tooth responded tender on percussion. Based on clinical and radiographic evidences, a diagnosis of pulpal necrosis with acute

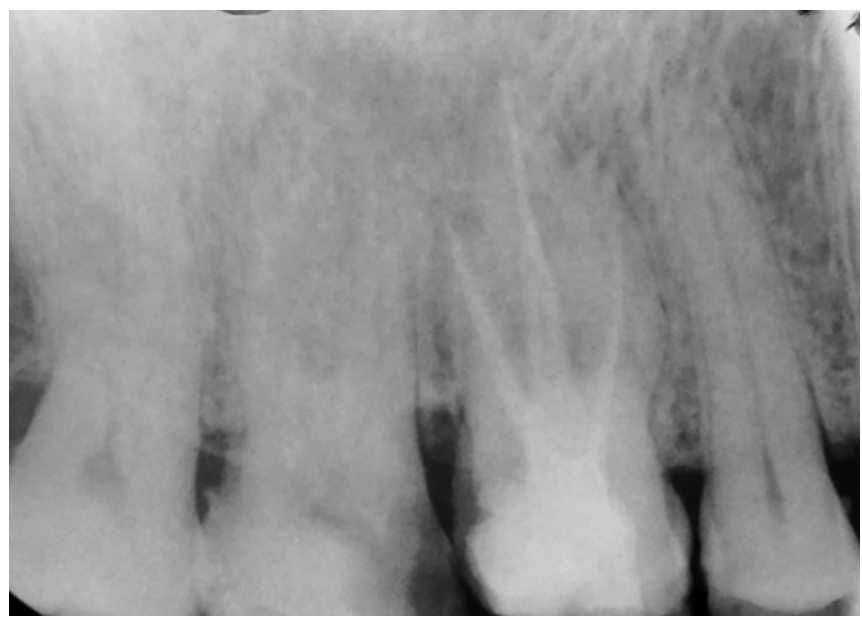

Fig. 1: Preoperative intraoral periapical radiograph

(c) The Author(s). 2020 Open Access This article is distributed under the terms of the Creative Commons Attribution 4.0 International License (https:// creativecommons.org/licenses/by-nc/4.0/), which permits unrestricted use, distribution, and non-commercial reproduction in any medium, provided you give appropriate credit to the original author(s) and the source, provide a link to the Creative Commons license, and indicate if changes were made. The Creative Commons Public Domain Dedication waiver (http://creativecommons.org/publicdomain/zero/1.0/) applies to the data made available in this article, unless otherwise stated. 
apical periodontitis in relation to \#27 was made and root canal treatment was initiated.

The tooth was anesthetized using $1.8 \mathrm{~mL}$ of $2 \%$ lidocaine containing 1:200,000 epinephrine (Xylocaine, AstraZeneca Pharma India Ltd., Bengaluru, India), under rubber dam isolation. Access preparation was prepared using Endo Access bur (DentsplyMaillefer, Ballaigues, Switzerland) in the left maxillary second molar. Initially, conventional triangular access was prepared and three canals (mesiobuccal, distobuccal, and palatal) were negotiated. As the palatal canal was located more distally, on further exploration toward the mesial side, a hemorrhagic spot was visible toward the mesial side, confirming two palatal canals (mesiopalatal, distopalatal) and the access cavity was then modified to the trapezoidal form. Careful manual exploration with the $10 \mathrm{~K}$ (Dentsply Maillefer Company, USA) file was done and working length was measured with electronic apex locator and confirmed radiographically (Fig. 2).

The root canals were cleaned and shaped by Neo Endo Rotary Files along with Glyde (15\%, Dentsply Maillefer Company, USA). The root canals were copiously irrigated with $2.5 \%$ sodium hypochlorite and saline. The calcium hydroxide dressing was placed in the canals for 1 week. The access cavity was temporized with Cavit-G (3M

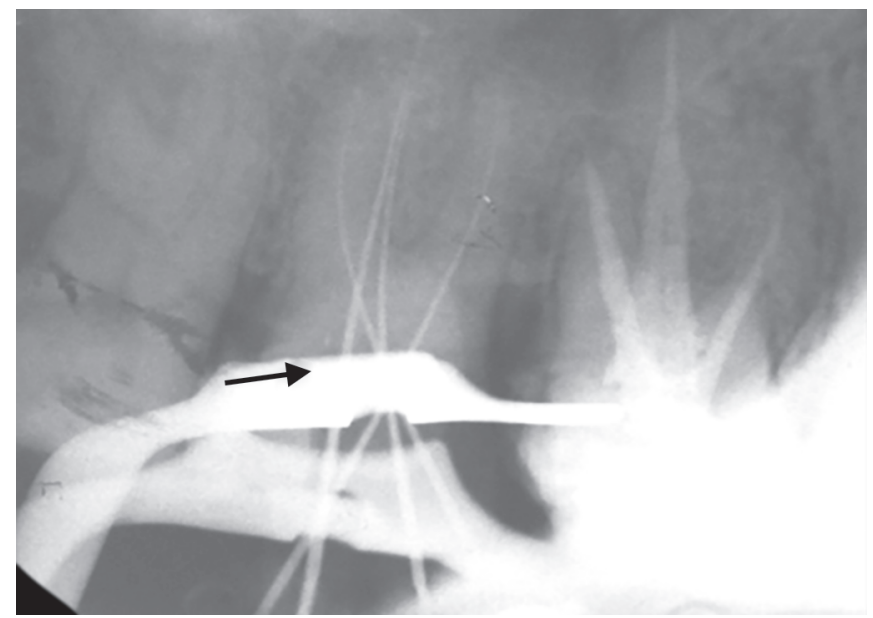

Fig. 2: Intraoral periapical radiograph of working length
EPSE, USA). Also, the patient was advised for cone-beam computed tomography $(\mathrm{CBCT})$ for better understanding of the palatal root canal morphology.

The CT scan images (Fig. 3) confirmed that the tooth has one palatal root with two separate root canals starting from coronal third till the middle third of the palatal root, and eventually join in the apical third.

The patient was recalled after 1 week; the tooth was asymptomatic. Root canals were irrigated again with normal saline. Final rinsing of the canals was done with root canal irrigant ( $2 \%$ chlorhexidine digluconate, Prevest Chlor X). Canals were then dried using paper points. Before obturation, master points were seated to test their suitability to canals and radiograph was taken (Fig. 4). The canals were obturated with selected master guttapercha cone and $\mathrm{AH}$-Plus sealer (Dentsply Maillefer Company, USA) and again radiograph was taken (Fig. 5).

\section{Discussion}

Based on the dental literature, it is evident that thorough knowledge of the anatomic morphology of the maxillary molars is essential for the success of root canal treatment. Anatomic variations can be found in the first as well as in the second maxillary molars.

Christie and Thompson ${ }^{5}$ have recommended to modify the outline to an ovoid shape so that the roof of the chamber is more parallel to the mesial marginal ridge. Maxillary second molars with two palatal canals usually have wide mesiodistal dimensions over the palatal cusps; for this reason, a trapezoidal access opening would be more desirable.

The disadvantage with using a conventional radiograph is that it is only a 2-D image of a 3-D object, which results in superimposition of the images. Newer diagnostic imaging modality such as volumetric computerized tomography or CBCT has been used for effective evaluation of root canal morphology. ${ }^{6}$ Along with that, detailed exploration of pulpal floor under proper illumination and magnification increases the possibility of detecting and treating the whole pulp system with aberrant morphology.

On the basis of number of canals from orifice to apex, ${ }^{7}$ Weine et al. categorize root canal configurations within a single root into four basic types - type I (1-1): single canal runs from orifice to apex type II (2-1): two canals arise from pulp chamber and unite into one
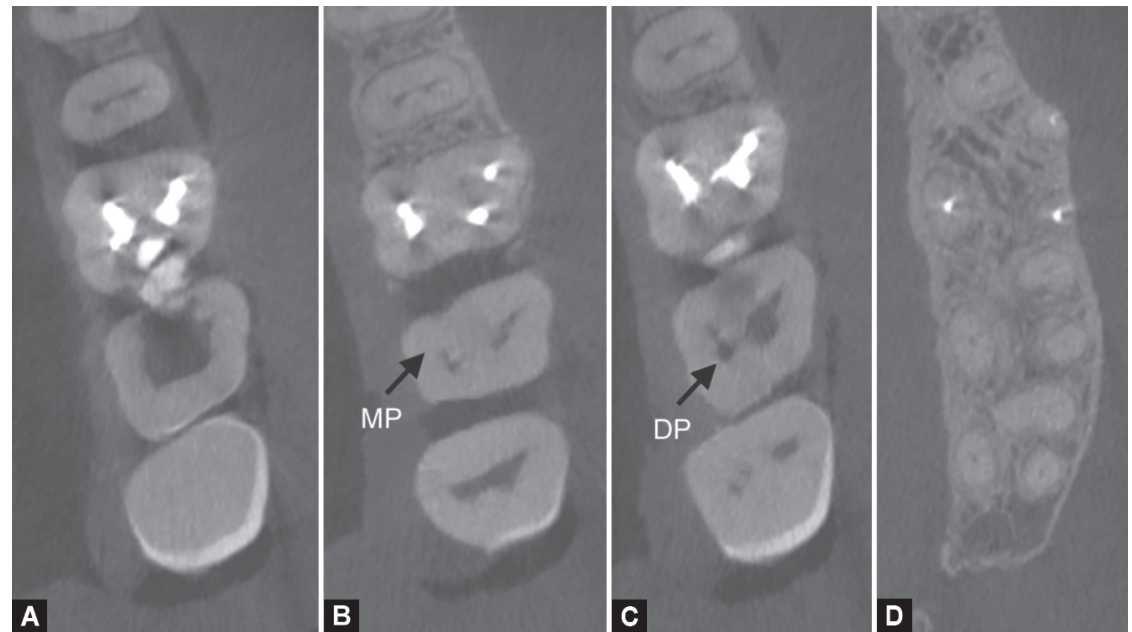

Figs 3 A to D: Cone-beam computed tomography images showing distopalatal (DP) and mesiopalatal (MP) canals in maxillary second molar (starting from coronal third and merging in the apical third of palatal root) 


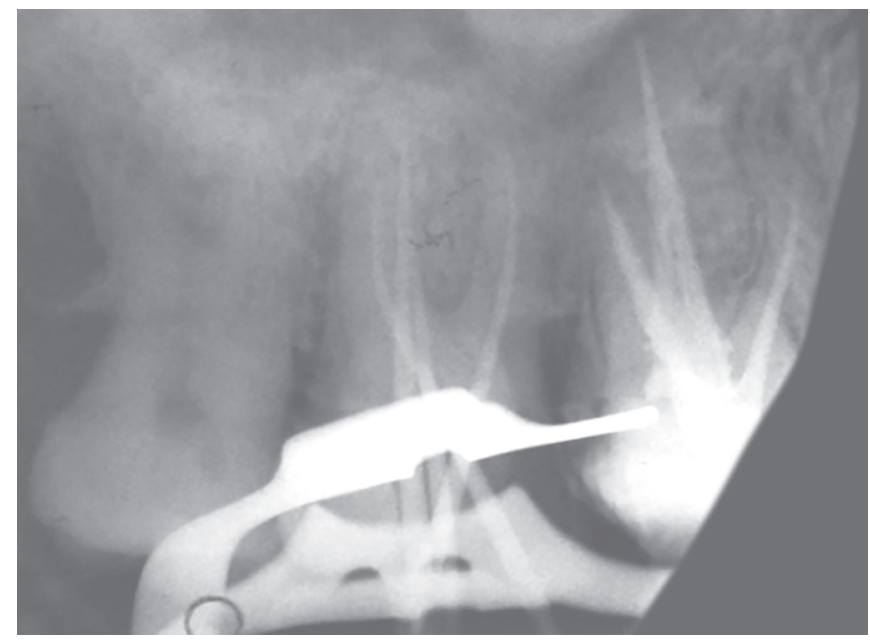

Fig. 4: Intraoral periapical radiograph of master cone

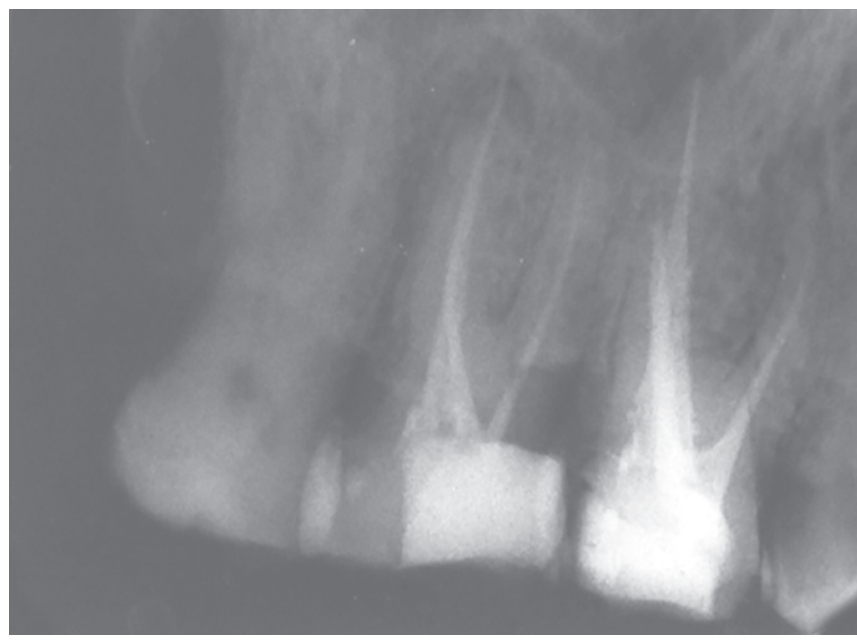

Fig. 5: Intraoral periapical radiograph of obturation

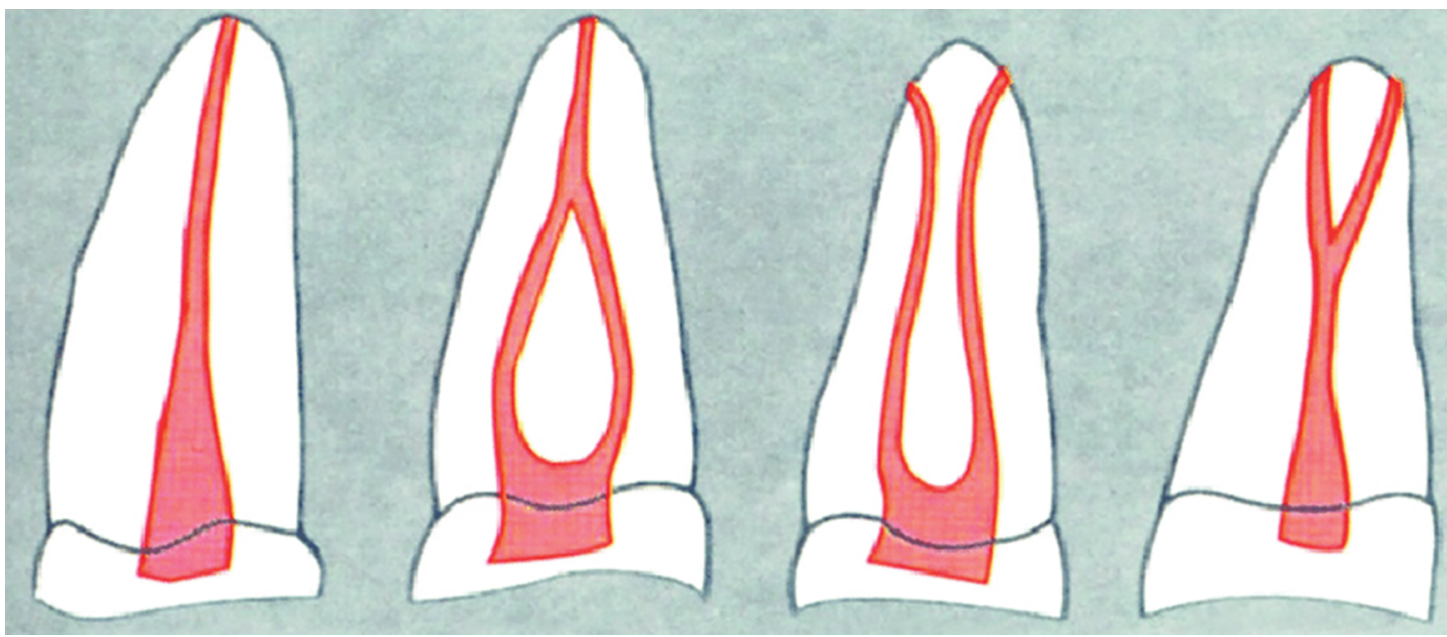

Fig. 6: Weine's classification of root canal configuration

during the course; type III (2-2): two canals run separately from orifice to apex; and type IV (1-2): one canal arises from floor of pulp chamber and divides into two during its course (Fig. 6).

Peikoff et al. ${ }^{8}$ in a retrospective study reported six variations of a second maxillary molar, having three distinct roots and canals in $56 \%$, three separate roots and four canals (two mesiobuccal canals) in $22.7 \%$, three roots and canals uniting mesiobuccal and distobuccal canals in 9\%, two separate roots and canals in $6.9 \%$, single root with one canal in $3.1 \%$, and four roots or canals including two palatal canals in $1.4 \%$ cases. According to the above classification, the case report falls into the latter group (type VI) and according to the Weine's root canal morphology classification, it falls under type II category.

\section{Conclusion}

When considering possibility of rare anatomical deviations, evaluation of radiographs taken with different angles and meticulous assessment of the pulp chamber is critical for adequate endodontic treatment of root canals and possible accessory canals. The use of CBCT, magnification (surgical loupes and dental operating microscope), and additional lighting (fiber-optic illumination) are recommended for successful management of the complex root canal system.

\section{References}

1. Pécora JD, Woelfel JB, Sousa Neto MD, et al. Morphologic study of the maxillary molars. Part Il: internal anatomy. Braz Dent J 1992;3(1):53-57.

2. Gopikrishna V, Reuben J, Kandaswamy D. Endodontic management of a maxillary first molar with two palatal roots and a single fused buccal root diagnosed with spiral computed tomography - a case report. Oral Surg Oral Med Oral Pathol Oral Radiol Endod 2008;105(4):e74e78. DOI: 10.1016/j.tripleo.2007.11.022.

3. Benenati FW. Maxillary second molar with two palatal canals and a palatogingival groove. J Endod 1985;11(7):308-310. DOI: 10.1016/ S0099-2399(85)80163-1.

4. Shojaeian SH, Ghoddusi J, Hajian S. A case report of maxillary second molar with two palatal root canals and a furcal enamel pearl. Iran Endod J 2013;8(1):37-39.

5. Christie WH, Thompson GK. The importance of endodontic access in locating maxillary and mandibular molar canals. J Can Dent Assoc 1994;60(6):527-536.

6. Nair MK, Nair UP. Digital and advanced imaging in endodontics: A review. J Endod 2007;33(1):1-6. DOI: 10.1016/j.joen.2006.08.013.

7. Bansal R, Hegde S, Astekar MS. Classification of root canal configurations: a review and a new proposal of nomenclature system for root canal configuration. J Clin Diagnos Res 2018;12(5):ZE01ZE0511615. DOI: 10.7860/JCDR/2018/35023.11615.

8. Peikoff MD, Christie WH, Fogel HM. The maxillary second molar: variations in the number of roots and canals. Int Endod J 1996;29(6):365-369. DOI: 10.1111/j.1365-2591.1996.tb01399.x. 